\title{
General practice under the hammer
}

The best career decision I have made so far was to leave my partnership in a pleasant practice in a nice part of Newcastle to work in a struggling practice in a needy part of Sunderland as a salaried GP. At the age of 47 this might very reasonably be put down to a straightforward case of mid-life crisis. The notion of really 'making a difference' in the world is something that often appeals when one sees less years ahead of you than are behind you. The real motivation was probably much more to do with people like Julian Tudor Hart who coined the phrase 'The Inverse Care Law' and spent his life trying to address it in a deprived mining community in Wales.

The practice I joined had been unable to recruit a GP for over 2 years, being reliant entirely on GP locum support. Despite the huge challenge facing them, they had continued to provide a personal and caring service to 'their' patients through sheer determination and hard work. My role was simply to act as a catalyst for a team who already epitomised the best of the NHS with their enormous commitment and goodwill in seeking to provide the best of care with very limited resources.

The practice quickly developed, soon becoming a GP training practice and achieving nearly full QOF points. The patients repeatedly expressed their delight at once again 'having their own doctors' and especially 'having doctors who listened'. The PCT meanwhile were starting to progress their plans to let go of the management of the practice. They were clearly under some pressure to focus on commissioning rather than providing but also to develop a 'plurality of providers' within the PCT. Despite considerable opposition from the patients and the local GP community, the PCT chose to put the practice out to competitive tendering, referencing undisclosed legal advice on the matter.

The practice was advertised in January 2007. There had been a significant number of expressions of interest in the practice even before it had been advertised which caused us considerable concern. We understand that 12 businesses made application at the prequalification stage, four were shortlisted, and two were invited for interview. In April 2007 we were informed that we had been chosen as the preferred bidder and in September we signed a contract as the preferred provider of services for the 4000 patients of this small practice.

Clearly this 'victory' was well received by the team, the patients, and the local GP community. The team had felt extremely vulnerable recognising what was something of a David and Goliath situation. The patients had been extremely vocal in their support, expressing outrage that the PCT were willing to jeopardise the high quality and continuity of care that had been re-established in the practice. This was a victory for people power, but also perhaps for a PCT that had been prompted to seriously listen to the patient's voice.

For my GP colleague and myself the journey has been an extremely challenging and often rather bruising one. The process had all the hallmarks of one designed for big business. Even at the first hurdle of completing the Prequalification Questionnaire we struggled as we were required to provide 3 years of accounts for our business. Not easy to do as salaried employees of a PCT. Continuing to work as full-time GPs, the business planning process was not only very time consuming and a massive distraction from caring for our patients, but was also extremely expensive. It is doubtful if we would have been successful in our bid without some excellent consultancy support and advice which, alongside various other set-up costs, has resulted in us looking to finish the first year in deficit while taking an income well below that of an average GP.

The cost in emotional terms is hard to quantify. The goodwill of a team who have repeatedly gone the 'second mile' for their patients and have then found themselves tossed out to the vagaries of the market place has inevitably resulted in a sense of feeling devalued and even betrayed. The language of the PCT often seemed cold and rather calculating. They were simply engaging in a standard competitive tendering process, the sort found in any other area of business. GPs, and especially GPs employed by their own organisation, had no automatic right to this valuable contract. They were dealing with the 'disposal' of a directly managed practice with a list of patients and employees and they were required to follow due process. The patients and staff of the practice were primarily appealing to the application of common sense and natural justice, but with a voice that came from the heart as much as the mind.

Paul Hodgkin describes this clash of cultures where the market economy of the NHS meets what he calls the 'gift culture'. ${ }^{1}$ This is the economy, so often found within small teams in primary healthcare, marked by a competition directed to how much one can give. Now, as a new independent contractor, I find myself back in the fold with my GP colleagues. The press depicts us as money grabbing, lazy, and self interested. Without a doubt there are some in the GP community who are just that, but the vast majority of GPs provide an efficient, personal, and high quality service on behalf of the NHS with an enormous commitment to their staff, their patients, and the local community.

But of course I am now just another business in the NHS. I have been matched against the other potential providers and have been found to provide the best value for money. The criteria for making this decision were wide-ranging and often challenging, but, I have no doubt, fail to measure many of the most important factors that result in excellent personal health care provided by small teams in communities across this land. Aiden Halligan, speaking at the PharmaTimes Great Oxford Debate in September 2007 described some of the factors that encapsulate the essence of good general practice: 'Patients want kindness, they want honesty, they want good communication, and they want respect 
and trustworthiness, and they get that from inspired frontline staff. The only obstruction to a patient-centred health service is not structural or technical - it is practice and custom and tradition'.2

GPs now find themselves having to match up to huge commercial businesses. While it could be argued that the primary interest of these large businesses is to extract maximum profit from the NHS to serve their shareholders, there is little doubt that they will be very focused on customer satisfaction. Certainly they will be able to access the economies of scale found in larger organisations. Meanwhile, most GP surgeries still operate on a model more akin to a corner shop than a modern service provider.

We appear to be facing an unequal challenge. The key task we face as practitioners and as a profession is to prove our worth, not only within the market economy of the NHS but to the patients who receive from and also pay for the NHS. I find myself exasperated listening to colleagues who argue against providing extended opening as a matter of principle, when quite clearly a significant proportion of patients have quite reasonable expectations of accessing this service and would certainly prefer to receive it from their 'own doctors' rather than from an impersonal polyclinic. We need to be able to demonstrate our worth in these essential areas of measurable service.

The practice, custom, and tradition of general practice is currently under great threat. Roger Jones describes the steady erosion in the skills, attitudes, values, and behaviours of general practice which seem to be resulting in an increasingly expensive, fragmented and impersonal health service. ${ }^{3}$ The real challenge however, is for us to engage in devising processes that can measure the values and ideals that can make general practice a truly inspiring place to work in and receive care from. The RCGP has provided an excellent blueprint for this in it's recent publication The Future Direction of General Practice. ${ }^{4}$ The test is now for individual practitioners, practices, and GP communities to translate this and other models of excellence into their local situations before the complex and often fragile networks of organisation that have sustained general practice are lost for ever.

\section{Ashley Liston}

\section{REFERENCES}

1. Hodgkin P. Funding deficits, finding gifts. $\mathrm{Br} \mathrm{J} \mathrm{Gen}$ Pract 2004; 54: 478-479.

2. Halligan A. This House Believes that the NHS should be run by Tesco [debate]. PharmaTimes Great Oxford Debate, Oxford Union, September 2007.

3. Jones R. Dismantling general practice. Br J Gen Pract 2007; 57: 860-861.

4. RCGP. The Future Direction of General Practice - A roadmap. London, RCGP: 2007.

http://www.rcgp.org.uk/pdf/Roadmap_embargoed $\% 2$ $011 \mathrm{am} \% 2013 \% 20$ Sept.pdf (accessed 6 Mar 2008).

DOI: 10.3399/bjgp08X280344 